\title{
Secondary Copper Smelters as Sources of Chlorinated and Brominated Polycyclic Aromatic Hydrocarbons
}

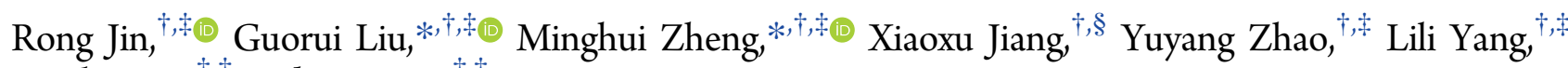

Xiaolin $\mathrm{Wu}^{\dagger,+}$ and Yang $\mathrm{Xu}^{\dagger,+}$

${ }^{\dagger}$ State Key Laboratory of Environmental Chemistry and Ecotoxicology, Research Center for Eco-Environmental Sciences, Chinese Academy of Sciences, P.O. Box 2871, Beijing 100085, China

${ }^{\ddagger}$ University of Chinese Academy of Sciences, Beijing 100049, China

${ }^{\S}$ China National Environmental Monitoring Centre, Beijing 100012, China

Supporting Information

ABSTRACT: The generation of and extent to which chlorinated and brominated polycyclic aromatic hydrocarbons ( $\mathrm{Cl} / \mathrm{Br}$-PAHs) are formed and released from secondary copper smelters remain unknown. This field study, to our knowledge, is the first to identify secondary copper smelters as new sources of $\mathrm{Cl} / \mathrm{Br}$-PAHs. Mass concentrations of $\sum_{19} \mathrm{Cl}$-PAHs and $\sum_{19} \mathrm{Br}$-PAHs ranged from 5.8 to $271 \mathrm{ng} \mathrm{Nm} \mathrm{Nm}^{-3}$ and 0.59 to $52.4 \mathrm{ng} \mathrm{Nm}^{-3}$, respectively. A comparison of $\mathrm{Cl} / \mathrm{Br}-\mathrm{PAH}$ concentrations in stack gas and fly ash from secondary copper smelters indicated that the use of scrap copper as raw material or the addition of coal or heavy oil as reductant may contribute to the elevated formation and emission of $\mathrm{Cl} / \mathrm{Br}$-PAHs. Congener profiles of $\mathrm{Cl} / \mathrm{Br}$-PAHs in stack gas and fly ash from secondary copper smelters were different with those of $\mathrm{Cl} / \mathrm{Br}$-PAHs from waste incinerations and other
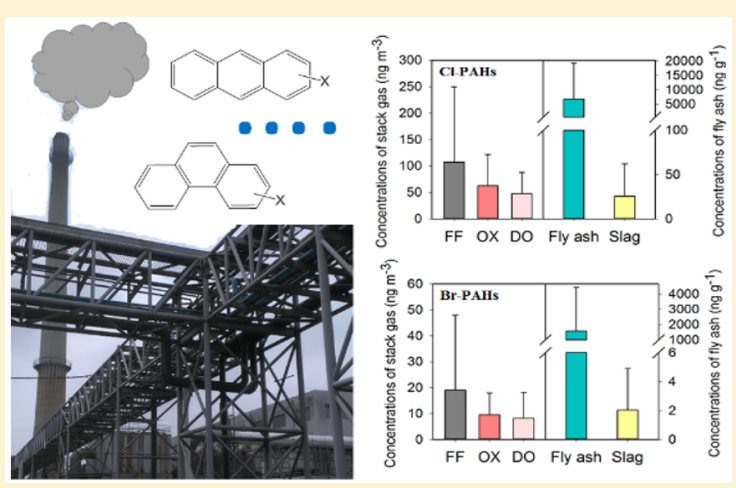
previously reported sources, thus could be used as possible fingerprints and source apportionments of environmental $\mathrm{Cl} / \mathrm{Br}$ PAHs. Atmospheric levels of $\mathrm{Cl} / \mathrm{Br}$-PAHs in the workplace or smelter surroundings were determined and potential exposures were assessed. Although chlorination of $\mathrm{PAHs}$ was previously recognized as an important formation pathway of $\mathrm{Cl} / \mathrm{Br}-\mathrm{PAHs}$, it was not verified to be the major formation pathway for $\mathrm{Cl} / \mathrm{Br}$-PAHs from secondary copper smelters in this study.

\section{INTRODUCTION}

Chlorinated and brominated polycyclic aromatic hydrocarbons $(\mathrm{Cl} / \mathrm{Br}$-PAHs) are derivatives of polycyclic aromatic hydrocarbons (PAHs) with one or more chlorine or bromine atoms substituted on the PAH molecules. ${ }^{1-5}$ Studies on AhRmediated activities of some $\mathrm{Cl}-\mathrm{PAH}$ and $\mathrm{Br}-\mathrm{PAH}$ congeners have indicated that their toxic potencies were higher than those of their parent PAH congeners. ${ }^{6-8}$ The occurrence characteristics of $\mathrm{Cl} / \mathrm{Br}-\mathrm{PAHs}$ in many environmental matrices have been reported. ${ }^{1,9-14}$ Monitoring results of Cl-PAHs in some environmental matrices, such as urban air samples in Japan and soil samples from chemical industrial complex areas, have suggested higher dioxin-like toxicities than those of notorious polychlorinated dibenzo- $p$-dioxins and dibenzofurans (PCDD/ Fs). ${ }^{6,15}$

$\mathrm{Cl} / \mathrm{Br}-\mathrm{PAHs}$ (>3 rings) are not intentionally manufactured commercial products; however, they can be formed as byproducts during the generation of polychlorinated biphenyls (PCBs), polychlorinated naphthalenes (PCNs), and polychlorinated terphenyls. $\mathrm{Cl} / \mathrm{Br}$-PAHs may also form during various anthropogenic activities and industrial thermal activities. Source identification and characterization of Cl-PAHs and Br-PAHs are the primary steps for recognizing their priority sources and controlling their emissions, which are significant for reducing their environmental and health risks. However, current recognition of the source category and characterization of $\mathrm{Cl}-$ $\mathrm{PAHs}$ and Br-PAHs is very lacking. Waste incineration and automobile emission have been identified as sources of $\mathrm{Cl}$ PAHs and Br-PAHs in previous studies. 2,12,16-18 E-waste dismantling has also been identified as an important source contributing to $\mathrm{Cl}-\mathrm{PAH}$ and $\mathrm{Br}-\mathrm{PAH}$ contamination in surrounding environments. ${ }^{15,19}$ However, with regard to many other industrial thermal processes that are possibly important sources of Cl-PAHs and Br-PAHs, the available data or knowledge concerning the occurrences and characterization of Cl-PAHs and Br-PAHs is still very scarce.

We speculated that secondary copper smelting processes might provide ideal conditions for the formation of Cl-PAHs and Br-PAHs considering the reasons given below. There are organic residuals, such as cable wrappings, wires, and polyvinyl chloride (PVC), in the feeding materials of secondary copper

Received: April 19, 2017

Revised: June 22, 2017

Accepted: June 23, 2017

Published: June 23, 2017 
Table 1. Basic Information on the Investigated Secondary Copper Smelting Plants

\begin{tabular}{|c|c|c|c|c|c|}
\hline denotation & $\mathrm{C} 1$ & $\mathrm{C} 2$ & C3 & $\mathrm{C} 4$ & $\mathrm{C} 5$ \\
\hline furnace & reverberator & NGL furnace & reverberator & reverberator & reverberator \\
\hline $\begin{array}{l}\text { raw } \\
\text { materials }\end{array}$ & $\begin{array}{l}\text { scrap copper; blister copper; } \\
\text { anode copper; }(1: 1: 2)\end{array}$ & $\begin{array}{l}\text { scrap copper; blister copper; anode } \\
\text { copper; }(1: 2: 0.4)\end{array}$ & $\begin{array}{l}\text { scrap copper; blister copper; anode } \\
\text { copper; }(1.7: 4: 1)\end{array}$ & $\begin{array}{l}\text { scrap copper; sheet } \\
\text { copper; }(1: 3)\end{array}$ & scrap copper \\
\hline fuel & coal tar & natural gas & heavy oil & heavy oil & heavy oil \\
\hline oxidant & compressed air & compressed air & compressed air & compressed air & $\underset{\text { air }}{\text { compressed }}$ \\
\hline reductant & coal & natural gas & coal & coal & coal \\
\hline $\begin{array}{l}\text { annual } \\
\text { capacity }\end{array}$ & $170 t / d$ & $250 t / d$ & $125 \mathrm{t} / \mathrm{d}$ & $264 t / d$ & $360 t / d$ \\
\hline $\mathrm{APCD}$ & bag filter & bag filter; settling chamber & bag filter & bag filter & bag filter \\
\hline
\end{tabular}

smelters that may provide carbon sources for the formation of $\mathrm{Cl} / \mathrm{Br} \mathrm{PAHs} .^{20,21}$ Additionally, residues of PVC or brominated flame retardants (BFRs) in cable wrappings and printed circuit boards may provide chlorine and bromine sources for the formation of $\mathrm{Cl} / \mathrm{Br}$-PAHs. E-waste plastic has also been proposed to be treated in smelters. ${ }^{22}$ Moreover, a high content of copper or cupric oxide could further catalyze their formation reactions during the thermal smelting processes. ${ }^{23-26}$ Halogenated aromatic compounds with similar structures to $\mathrm{Cl}$ PAHs and Br-PAHs, such as PCNs, dioxins (PCDD/Fs), and brominated dioxins (PBDD/Fs), have been confirmed to be significantly formed during secondary copper smelting. ${ }^{20,27,28}$ Therefore, it is very likely that $\mathrm{Cl} / \mathrm{Br}$-PAHs may form during secondary copper smelting, although there is no report regarding the emissions of $\mathrm{Cl} / \mathrm{Br}-\mathrm{PAH}$ from secondary copper smelters.

Secondary copper smelting is an important global industry. More than $20 \%$ of the refined copper produced in China is from the secondary copper smelting industry. Secondary copper production in China increased from 880 thousand tonnes to 2900 thousand tonnes from 2002 to 2015 , and was responsible for $34 \%$ of the world production in 2015. ${ }^{29}$ Previous studies regarding PCDD/Fs and PCNs have identified secondary copper smelting as a significant source that needs to be taken into consideration for priority control of unintentional persistent organic pollutants (POPs). ${ }^{30,31}$ Therefore, studying the levels and congener profiles of $\mathrm{Cl} / \mathrm{Br}-\mathrm{PAH}$ from secondary copper smelting sources is important for recognizing their origin sources in addition to controlling their emissions. The obtained data from this field study may also be helpful for developing emission inventory of Cl-PAHs and $\mathrm{Br}$-PAHs from the secondary copper smelting industry. Considering the persistence and long-range transport properties of POPs, the identification and characterization of new $\mathrm{Cl} / \mathrm{Br}-\mathrm{PAH}$ sources in China are also of critical global significance.

In this study, stack gas, fly ash, and slag were important releasing carriers of aromatic pollutants from five secondary copper smelting plants; samples were collected and analyzed for $\mathrm{Cl}-\mathrm{PAHs}$ and $\mathrm{Br}-\mathrm{PAHs}$ by isotopic dilution gas chromatography coupled with a high-resolution mass spectrometer method (GC/HRMS). Air samples in the workplace or surroundings of the secondary copper smelting plants were also collected and analyzed for evaluation of potential exposure to Cl-PAHs and Br-PAHs. The primary aims of this study were (1) to confirm whether the secondary copper smelting industry is an important new source of Cl-PAHs and Br-PAHs; (2) to characterize the congener profiles of Cl-PAHs and Br-PAHs from secondary copper smelting processes, which is important for recognition of their fingerprints and understanding their formation mechanisms; (3) to evaluate air inhalation of $\mathrm{Cl}$ -
PAHs and Br-PAHs in the workplace or surroundings of the smelting plants, which may provide important data for preliminarily assessing potential exposure and health risk.

\section{EXPERIMENTAL SECTION}

Information on the Investigated Plants. Five typical secondary copper smelting plants with different scales and operating techniques were investigated in this study. In China, most of the facilities used reverberators as their furnaces for copper smelting. Basic information on the investigated plants is listed in Table 1. One of the investigated facilities (C2) used an NGL furnace, which combines the techniques of titling furnaces and rotary furnaces. Scrap copper, blister copper, and anode copper were used as the raw materials in the investigated facilities. Organic residues (such as PVC and wire cables) had higher fractions in the scrap copper than in the blister copper and anode copper. ${ }^{20}$ Secondary copper smelting consisted of three stages: feeding-fusion (FF), oxidation (OX), and deoxidization (DO). Coal was used as the fuel in plant $\mathrm{C} 1$, natural gas was used in plant $\mathrm{C} 2$, and heavy oil was used in the other facilities. Bag filters were used as air pollution control devices (APCDs) in the plants for capturing particulate matter in the flue gases.

Sample Collection and Analysis of $\mathrm{Cl}-\mathrm{PAHs}$ and $\mathrm{Br}$ PAHs. Stack gases and solid residues, including fly ash and slag, are the dominant release routes of unintentional POPs. In order to evaluate the stack gas emissions and identify the important process stages where $\mathrm{Cl}-\mathrm{PAH}$ and $\mathrm{Br}-\mathrm{PAHs}$ form, stack gas samples from different smelting stages were collected for the $\mathrm{C} 1, \mathrm{C} 2$, and C3 plants using an automatic isokinetic sampling system (TCR TECORA, Italy) as described in previous studies. $^{20,32}$ Fly ash and slag samples were collected for evaluating the $\mathrm{Cl} / \mathrm{Br}-\mathrm{PAH}$ release by solid residues. Thirteen air samples located at or surrounding the $\mathrm{C} 1$ and $\mathrm{C} 2$ smelting plants were collected using high-volume samples (Echo Hi-Vol, Tecora Co., France) with the aim of evaluating the potential exposure and impact of source emissions on surroundings. ${ }^{33}$ The organic pollutants in the gaseous phase were absorbed onto polyurethane foam (PUF; Tisch Environmental), and particles were trapped on cleaned quartz fiber filters (QFFs). After sampling, isotopic dilution gas chromatography coupled with high-resolution mass spectrometry (GC/HRMS) was used to analyze the Cl-PAHs and Br-PAHs in the samples. Isotopic labeled internal standards of Cl-PAHs and Br-PAHs $\left({ }^{13} \mathrm{C}_{6}-9\right.$ chlorophenanthrene, ${ }^{13} \mathrm{C}_{6}$-2-chloroanthracene, ${ }^{13} \mathrm{C}_{6}$-1-chloropyrene, ${ }^{13} \mathrm{C}_{6}-7$-chlorobenz [a] anthracene, ${ }^{13} \mathrm{C}_{6}$-7-bromobenz [a]anthracene, and $\mathrm{d}_{9}$-9-bromophenanthrene) were added into the samples before extraction. The stack gas, fly ash and slag samples were Soxhlet-extracted by toluene, and the air samples were extracted by a 1:1 mixture of hexane and dichloromethane 

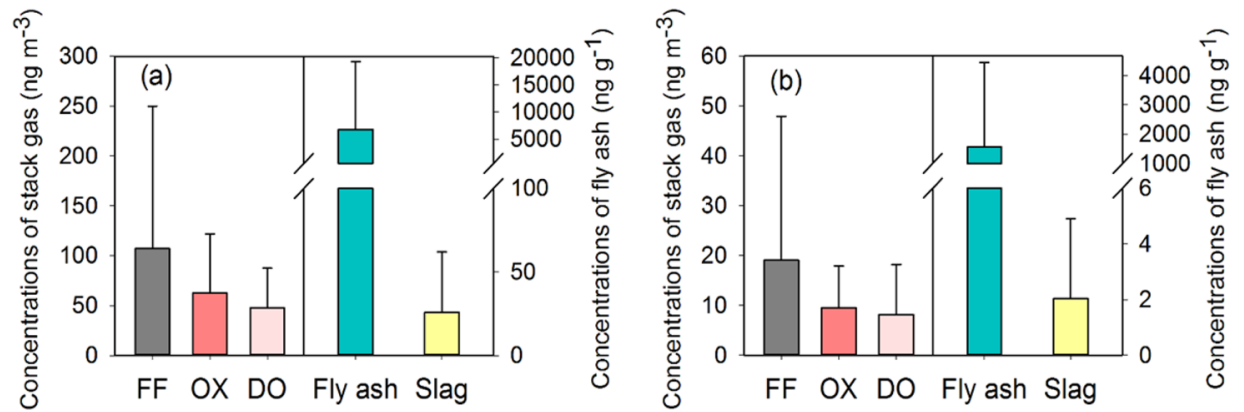

Figure 1. Average concentrations of Cl-PAHs and Br-PAHs in stack gas, fly ash, and slag samples from secondary copper smelting processes. (a) Concentrations of Cl-PAHs; (b) concentrations of Br-PAHs.

by accelerating solvent extraction (ASE). The extracts were then cleaned using an active silica gel column; its silica was baked beforehand at $450{ }^{\circ} \mathrm{C}$ for $6.5 \mathrm{~h}$. The extracts were then concentrated to approximately $50 \mu \mathrm{L}$ by a rotary evaporator and a gentle stream of nitrogen. Before instrumental analysis, an injection standard $\left({ }^{13} \mathrm{C}_{6}-7,12\right.$-dichlorobenz $[\mathrm{a}]$ anthracene $)$ was added. Separation of the Cl-PAH and Br-PAH congeners were performed using a DB-5 MS capillary column $(60 \mathrm{~m} \times$ $0.25 \mathrm{~mm} \times 0.25 \mu \mathrm{m})$. Detection of $\mathrm{Cl}-\mathrm{PAH}$ and $\mathrm{Br}-\mathrm{PAH}$ congeners was achieved in selected ion monitoring (SIM) mode at a resolution above 10000 . The detailed information for analysis of Cl-PAHs and Br-PAHs has been described in previous studies. ${ }^{34}$ PAHs in the samples were also analyzed according to the CalEPA Method 429. Recoveries of the labeled internal standards of Cl-PAHs and Br-PAHs were 70$108 \%$ in the solid samples, $43-94 \%$ in stack gas samples, and $49-103 \%$ in air samples. These recoveries were satisfactory for trace analysis of persistent organic pollutants (POPs) in environmental matrices using isotopic dilution GC/HRMS methods.

Calculations of the Toxic Equivalent Quantities (TEQs) of Cl-PAHs and Br-PAHs. Toxic equivalent factors (TEFs) of $\mathrm{Cl} / \mathrm{Br}-\mathrm{PAH}$ congeners have not been officially assigned by the World Health Organization (WHO). Therefore, the calculation of TEQs for $\mathrm{Cl} / \mathrm{Br}-\mathrm{PAHs}$ was based on previous studies regarding the AhR-mediated activities of several $\mathrm{Cl} / \mathrm{Br}-\mathrm{PAH}$ congeners reported using a YCM3 cell bioassay. ${ }^{6-8}$ Relative potency factors (RPFs) of the congeners relative to benzo[a]pyrene $(\mathrm{BaP})$ were defined $\left(\mathrm{RPF}_{\mathrm{BaP}}\right)$. In the YCM3 cell assay system, the potency of 2,3,7,8-tetrachlorodibenzo-p-dioxin $(2,3,7,8$-TCDD) was 60 times that of $\mathrm{BaP}$. As a result, the TEQ concentrations of Cl-PAHs and $\mathrm{Br}-\mathrm{PAH}$ s were calculated according to the following equation:

$$
\mathrm{TEQ}=\sum\left[C_{\mathrm{i}}\right] \mathrm{RPF}_{\mathrm{BaP}} / 60
$$

$C_{\mathrm{i}}$ is the concentration of the Cl-PAH and $\mathrm{Br}-\mathrm{PAH}$ congeners. $\mathrm{RPF}_{\mathrm{BaP}}$ is the RPF values of Cl-PAH and $\mathrm{Br}-\mathrm{PAH}$ congeners relative to $\mathrm{BaP}$. In this study, 38 congeners of $\mathrm{Cl}-\mathrm{PAHs}$ and $\mathrm{Br}$ PAHs were detected. However, among these congeners, there are only 17 congeners of which their $\mathrm{RPF}_{\mathrm{BaP}}$ were available in current publications. ${ }^{6-8}$ Therefore, the actual TEQs of $\mathrm{Cl}-$ PAHs and Br-PAHs might be even higher than that calculated in this study according to the above equation.

Calculations of Thermodynamic Parameters of $\mathrm{Cl}$ PAHs and Br-PAHs. Relative energies of the formation reactions of congeners can be calculated from Gibbs free energies. In order to determine which position of the PAH congeners is the most easily substituted position, thermody- namic properties for some $\mathrm{Cl}-\mathrm{PAH}$ and $\mathrm{Br}-\mathrm{PAH}$ congeners were calculated using density functional theory (DFT) based on isodesmic reactions. ${ }^{35-38}$ Because many more congeners of chlorinated phenanthrenes (ClPhes), chlorinated anthracenes (ClAnts), brominated phenanthrenes (BrPhes), and brominated anthracenes (BrAnts) were detected than that of other homologues, the chlorination or bromination of Phe and Ant were used as examples in this study. Relative energies of the congeners $(\Delta G)$ were calculated from the Gibbs free energies using the equations as shown below. Calculations were performed with the Gaussian 03 program package, using the ub3lyp/6-31+G(d, p) method.

$$
\begin{aligned}
& \mathrm{C}_{14} \mathrm{H}_{10-n} \mathrm{Cl}_{n}(\mathrm{a})+\mathrm{Cl} \cdot(\mathrm{b}) \rightarrow \mathrm{C}_{14} \mathrm{H}_{9-n} \mathrm{Cl}_{n+1}(\mathrm{c})+\mathrm{H} \cdot(\mathrm{d}) \\
& \mathrm{C}_{14} \mathrm{H}_{10-n} \mathrm{Br}_{n}(\mathrm{a})+\mathrm{Br} \cdot(\mathrm{b}) \rightarrow \mathrm{C}_{14} \mathrm{H}_{9-n} \mathrm{Br}_{n+1}(\mathrm{c})+\mathrm{H} \cdot(\mathrm{d}) \\
& \Delta G=G(\mathrm{c})+G(\mathrm{~d})-G(\mathrm{a})+G(\mathrm{~b})
\end{aligned}
$$

\section{RESULTS AND DISCUSSION}

Emission Levels and Influencing Factors of Cl-PAHs and Br-PAHs. Concentrations of $\sum_{19} \mathrm{Cl}-\mathrm{PAHs}$ and $\sum_{19} \mathrm{Br}$ $\mathrm{PAHs}$ in the stack gas samples from three different smelting stages of smelters are shown in Figure 1 and SI Table S1. Mass concentrations ranged from 5.8 to $271 \mathrm{ng} \mathrm{Nm}^{-3}$ for $\sum_{19} \mathrm{Cl}$ PAHs and from 0.59 to $52.4 \mathrm{ng} \mathrm{Nm}^{-3}$ for $\sum_{19} \mathrm{Br}$-PAHs. TEQ concentrations in the stack gas ranged from 13.3 to $1027 \mathrm{pg}$ TEQ $\mathrm{Nm}^{-3}$ for Cl-PAHs and from 0.32 to $13.7 \mathrm{pg}$ TEQ Nm$^{-3}$ for Br-PAHs (SI Table S1). These TEQ concentrations are important for evaluating the environmental risks presented by Cl-PAHs and Br-PAHs released from the smelters. TEQ concentrations of Cl-PAHs in the stack gas released from secondary copper smelters were slightly lower than that of PCDD/Fs reported in previous studies (0.009-2.86 ng TEQ $\left.\mathrm{Nm}^{-3}\right){ }^{20,21}$ However, the TEQ concentrations of Cl-PAHs were higher than those of PCBs and PCNs, which were 3-20 pg TEQ $\mathrm{Nm}^{-3}$ and $0.8-300$ pg TEQ $\mathrm{Nm}^{-3}$, respectively. ${ }^{20,28}$ This indicated a significant contribution of $\mathrm{Cl}-\mathrm{PAHs}$ and $\mathrm{Br}$ PAHs to total concentrations in mass and TEQ of dioxins and dioxin-like compounds. Therefore, $\mathrm{Cl} / \mathrm{Br}-\mathrm{PAHs}$, similar to POPs, should not be ignored for reducing environmental and health risks.

Fly ash is also an important carrier of pollutants emitted from industrial plants. ${ }^{30,39-41}$ Concentrations of Cl-PAHs and $\mathrm{Br}$ PAHs in fly ash and slag are shown in Figure 1 and SI Table S2. The mass concentrations in fly ash were $2.58 \mathrm{ng} \mathrm{g}^{-1}$ to $29.0 \mu \mathrm{g}$ $\mathrm{g}^{-1}$ for Cl-PAHs and $0.39 \mathrm{ng} \mathrm{g}^{-1}$ to $6.63 \mu \mathrm{g} \mathrm{g}^{-1}$ for Br-PAHs. 
TEQ concentrations of Cl-PAHs in fly ash were $0.014 \mathrm{ng}$ TEQ $\mathrm{g}^{-1}$ to $171 \mathrm{ng}$ TEQ $\mathrm{g}^{-1}$, while the TEQ concentrations of $\mathrm{Br}-$ PAHs were $0.12 \mathrm{pg} \mathrm{TEQ}^{-1}$ to $3.34 \mathrm{ng} \mathrm{TEQ} \mathrm{g}^{-1}$ (SI Table S2).

The concentrations of Cl-PAHs and Br-PAHs in both stack gas and solid residues varied largely among facilities. The composition of feeding materials is an important factor influencing the formation of unintentional POPs, ${ }^{42,43}$ whereas fractions of scrap copper is the important factor influencing the formation and release of POPs. ${ }^{20}$ In this study, the concentrations of Cl-PAHs and Br-PAHs in the fly ash of plant C5, which used the $100 \%$ scrap copper with many more organic residues as the raw materials, were highest, which further confirmed the important influence of raw material composition on the emission levels of Cl-PAHs and Br-PAHs. Our previous study on the formation and emission of PCDD/ Fs and PCBs from secondary copper smelters, which contained $0 \%, 30 \%$, and $100 \%$ scrap copper in the raw materials, also confirmed the significant influence that raw material composition has on $\mathrm{PCDD} / \mathrm{F}$ and $\mathrm{PCB}$ formation and emission. ${ }^{20}$ The fractions of scrap copper in raw materials used in plants $\mathrm{C} 1, \mathrm{C} 2$, and $\mathrm{C} 3$ were similar. An obvious difference was the fuel and reductant used in the $\mathrm{C} 1, \mathrm{C} 2$, and $\mathrm{C} 3$ plants. Coal, natural gas, and heavy oil were separately used as the fuel in plants $\mathrm{C} 1, \mathrm{C} 2$, and $\mathrm{C} 3$, respectively. Coal was used as the reductant in the deoxidization stage of plants $\mathrm{C} 1$ and $\mathrm{C} 3$, while natural gas was used as the reductant in C2. It is widely recognized that coal and heavy oil can provide important carbon sources or precursors for the formation of PAHs. ${ }^{44-48}$ Therefore, using natural gas to substitute coal and heavy oil as fuel and reductant may help to reduce the yield of Cl-PAHs and $\mathrm{Br}$-PAHs during secondary copper smelting processes. This was consistent with the finding that the concentrations of Cl-PAHs and Br-PAHs in both the stack gas and fly ash from C2 using natural gas as the fuel and reductant were much lower than that of $\mathrm{C} 1$ using coal as the fuel and reductant and C 3 using heavy oil as fuel and coal as reductant.

Emission Factors and Emission Estimations of $\mathrm{Cl}-$ PAHs and Br-PAHs. Calculation of the emission factors may be useful for preliminarily evaluating the total annual emissions of Cl-PAHs and Br-PAHs from the secondary copper smelting industry, and thus help establish emission inventories. Emission factors based on the mass and TEQ concentrations of Cl-PAHs and Br-PAHs in stack gas and residues were calculated using the following equations:

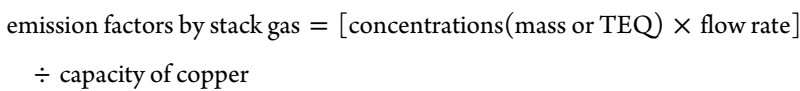

In order to evaluate the contributions of different smelting stages to the emissions of Cl-PAHs and Br-PAHs in the whole process line, the emission amounts of $\mathrm{Cl}-\mathrm{PAHs}$ and $\mathrm{Br}-\mathrm{PAHs}$ from different smelting stages by stack gas normalized to per tonne of copper production were calculated and shown in Figure 2. Emissions of Cl-PAHs and Br-PAHs from the feedingfusion (FF) stage were 2-3 times higher than that of the oxidation (OX) stage, and much higher than that of the deoxidation (DO) stage. This indicated that FF and OX were the dominant emission stages of Cl-PAHs and Br-PAHs from secondary copper smelting processes, which is important
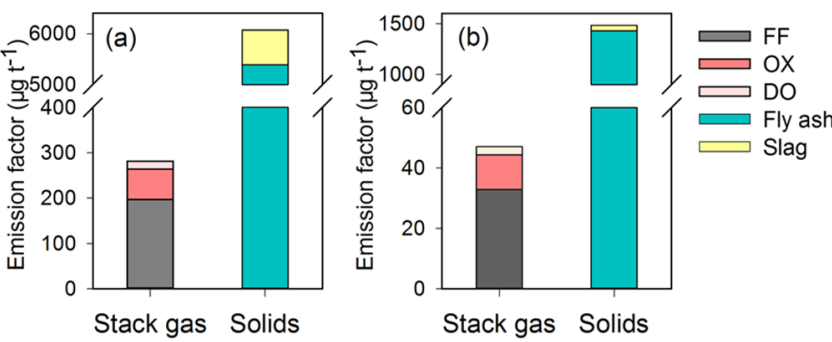

Figure 2. Average emission factors of $\mathrm{Cl}-\mathrm{PAH}$ and $\mathrm{Br}-\mathrm{PAH}$ through stack gas and solids. (a) emission factors of Cl-PAHs; (b) emission factors of Br-PAHs; FF: feeding-fusion stage; $\mathrm{OX}$ : oxidation stage; DO: deoxidization stage.

information for developing techniques to control and reduce their emissions from the priority smelting stages.

Mass emission factors of Cl-PAHs and Br-PAHs by stack gas and solid residues are shown in Figure 2. Emission factors were $0.22 \mathrm{mg} \mathrm{t}^{-1}$ to $10.0 \mathrm{mg} \mathrm{t}^{-1}$ and $0.081 \mathrm{mg} \mathrm{t}^{-1}$ to $3.82 \mathrm{mg} \mathrm{t}^{-1}$ for $\mathrm{Cl}-\mathrm{PAH}$ and Br-PAHs, respectively. More than $90 \%$ of the total Cl-PAHs and Br-PAHs were released by the solid residues. This indicated the strong absorption abilities of Cl-PAHs and Br-PAHs by residues and the necessity of environmentally sound disposal of solid residues. Atmospheric emission factors of Cl-PAHs and Br-PAHs by stack gas were $10.2-528 \mu \mathrm{g} \mathrm{t}^{-1}$ and $1.18-98.9 \mu \mathrm{g} \mathrm{t}^{-1}$, respectively.

TEQ emission factors for Cl-PAHs and Br-PAHs were also calculated (SI Table S3). TEQ emission factors were $1.21 \mu \mathrm{g}$ TEQ $\mathrm{t}^{-1}$ to $85.3 \mu \mathrm{g} \mathrm{TEQ}^{-1}$ for Cl-PAHs and $10.5 \mathrm{ng} \mathrm{TEQ}^{-1}$ to $1305 \mathrm{ng} \mathrm{TEQ} \mathrm{t}^{-1}$ for Br-PAHs. More than $80 \%$ of the total TEQs were contributed by the solid phase, which further emphasized the need for better control of solid residues. The TEQ emission factors by stack gas were $0.022 \mu \mathrm{g}^{\text {TEQ }} \mathrm{t}^{-1}$ to $1.94 \mu \mathrm{g}$ TEQ $\mathrm{t}^{-1}$ for Cl-PAHs and $0.69 \mathrm{ng}^{\mathrm{T}} \mathrm{TEQ} \mathrm{t}^{-1}$ to $25.8 \mathrm{ng}$ TEQ $\mathrm{t}^{-1}$ for Br-PAHs.

Average emission factors of Cl-PAHs and Br-PAHs by stack gas and solid residues in this study and the production of secondary copper in 2015 of China (2,900 thousand tonnes) were adopted for preliminary estimation of the annual emissions of Cl-PAHs and Br-PAHs by the secondary copper smelting industry. The annual total emissions of Cl-PAHs were preliminarily estimated to be approximately $0.81 \pm 0.75 \mathrm{~kg}$ $(3.13 \pm 2.83 \mathrm{~g}$ TEQ $)$ by stack gas, $15.6 \pm 13.7 \mathrm{~kg}(154 \pm 132 \mathrm{~g}$ TEQ $)$ by fly ash, and $1.99 \pm 2.76 \mathrm{~kg}(1.92 \pm 2.38 \mathrm{~g}$ TEQ $)$ by slag. Total emissions of Br-PAHs were estimated to be approximately $0.14 \pm 0.14 \mathrm{~kg}(0.037 \pm 0.037 \mathrm{~g}$ TEQ $)$ by stack gas, $4.14 \pm 5.79 \mathrm{~kg}(1.69 \pm 1.87 \mathrm{~g}$ TEQ $)$ by fly ash, and $0.16 \pm 0.22 \mathrm{~kg}(0.01 \pm 0.01 \mathrm{~g}$ TEQ $)$ by slag. This data may be helpful for establishing the preliminary emission inventory of $\mathrm{Cl}-\mathrm{PAH}$ and Br-PAHs.

Congener Profiles of $\mathrm{Cl}-\mathrm{PAHs}$ and Br-PAHs. Congener profiles are important for tracing the sources of environmental pollutants. This is the first study that reported the congener profiles of Cl-PAHs and Br-PAHs during secondary copper smelting. Abbreviations of the congeners are given in SI Table S4. As shown in Figure 3, 9-chlorophenanthrene/2-chlorophenanthrene (9-ClPhe/2-ClPhe) was the major Cl-PAH congener in both stack gas and fly ash, accounting for more than $38 \%$ in stack gas, $17 \%$ in fly ash, and $34 \%$ in slag. Other congeners, such as 1,5-dichloroanthracene/9,10-dichloroanthracene (1,5$\left.\mathrm{Cl}_{2} \mathrm{Ant} / 9,10-\mathrm{Cl}_{2} \mathrm{Ant}\right), 9,10$-dichlorophenanthrene $(9,10$ $\mathrm{Cl}_{2} \mathrm{Phe}$ ), 3-chlorofluoranthene (3-ClFlu), and 1-chloropyrene (1-ClPyr) were also dominant Cl-PAH congeners. Cl-PAH 


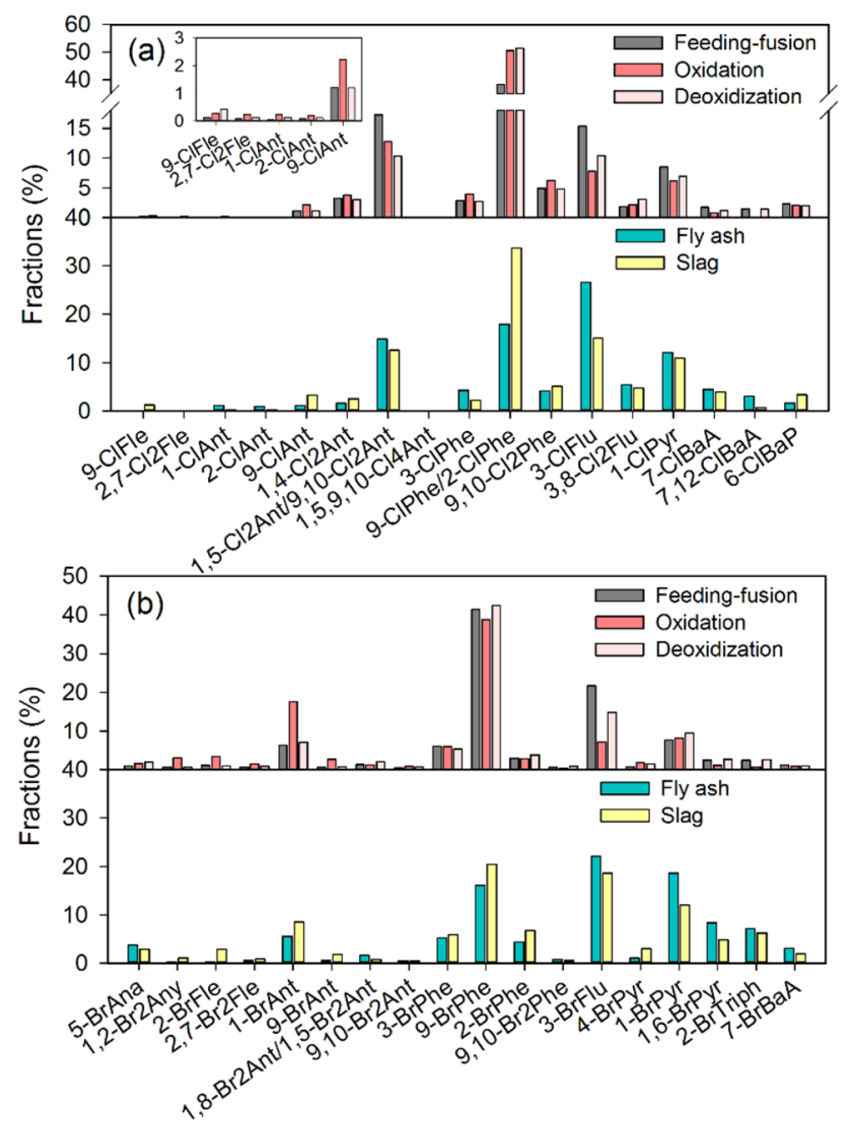

Figure 3. Congener profiles of $\mathrm{Cl}-\mathrm{PAHs}$ and $\mathrm{Br}-\mathrm{PAHs}$ in the stack gas, fly ash and slag samples. (a) Cl-PAHs; (b) Br-PAHs.

congeners of higher molecular weights tended to have higher fractions in solids than in stack gas, because their vapor pressures were lower than congeners of low molecular weights. The congener distributions of Cl-PAHs in the stack gas of secondary copper smelting facilities were different from those in the stack gas of waste incinerators, of which 1-ClPyr had high fractions (approximately 50\%). ${ }^{16} \mathrm{Cl}-\mathrm{PAH}$ distributions in the fly ash of secondary copper smelting were also different from previous studies on fly ash of waste incinerators, which reported a dominance of 6-chlorobenzo[a]pyrene (6-ClBaP) (31.2\%) and $1-\mathrm{ClPyr}(12.8 \%){ }^{2}$ In regards to the $\mathrm{Br}-\mathrm{PAH}$ congener profiles, 9-bromophenanthrene (9-BrPhe) (>38\%) was the major congener in stack gas, and 9-BrPhe and 3-bromofluoranthene $(3-\mathrm{BrFlu})$ were the major congeners in solid residue samples. The distributions of Br-PAHs in the fly ash of secondary copper smelting facilities were also different from those in the fly ash of waste incinerators, which were dominated by 1-bromopyrene (1-BrPyr), 6-bromobenzo[a]pyrene (6$\mathrm{BrBaP})$, and 7-bromobenzo[a] anthracene $(7-\mathrm{BrBaA}){ }^{2}$ Similar with Cl-PAHs, the Br-PAH congeners with high molecular weights also had higher fractions in the solids than in the stack gas.

Ratios of the concentrations of certain specific congeners can provide important information for source apportionment. The ratios of $6-\mathrm{ClBaP} / 1-\mathrm{ClPyr}$, 3-ClFlu/1-ClPyr, 7-chlorobenzo[a] anthracene (7-ClBaA)/1-ClPyr, 6-ClBaP/3-ClFlu, 1-ClPyr/ $3-\mathrm{ClFlu}$, and $7-\mathrm{ClBaA} / 3-\mathrm{ClFlu}$ have been used to trace the sources of Cl-PAHs in previous studies. ${ }^{2,15,49}$ Moreover, the ratios of 7-BrBaA/1-BrPyr and 9-BrPhe/1-BrPyr have been used to trace the sources of Br-PAHs. ${ }^{2}$ In this study, the ratios of 3-BrFlu/1-BrPyr, 1-BrPyr/3-BrFlu, 7-BrBaA/3-BrFlu, and 9$\mathrm{BrPhe} / 3-\mathrm{BrFlu}$ were also calculated. The ranges of the ratios are shown in Table 2. Ratios of 1-ClPyr/3-ClFlu were $0.10-$ 1.35 in solids from secondary copper smelting, which were lower than those for waste incineration fly ash with average ratio values of $1.53 .^{2}$ PCA analysis of the Cl-PAH congener ratios in stack gas and fly ash from secondary copper smelters, waste incinerators, and samples from e-waste dismantling areas was conducted (SI Figure S1). There was a distinction among ratios of congeners for secondary copper smelting facilities, waste incinerations, and e-waste dismantling processes. This suggested that there are significant differences in the Cl-PAH congener profiles between the secondary copper smelting processes, waste incinerations, and e-waste dismantling processes. Therefore, congener profiles of Cl-PAHs from secondary copper smelters can be used as possible fingerprints and source apportionments of Cl-PAHs from secondary copper smelting sources.

Is Chlorination the Dominant Formation Pathway of Cl-PAHs During Secondary Copper Smelting? Formation mechanisms of Cl-PAHs and $\mathrm{Br}$-PAHs during industrial thermal processes have remained unclear up to now. In previous studies, it was assumed that chlorination was an important pathway of Cl-PAHs secondary formed in air. ${ }^{50}$ The chlorination pathway was supported by a study that reported

Table 2. Ratios of Specific Cl-PAH and Br-PAH Congeners

\begin{tabular}{|c|c|c|c|c|c|c|}
\hline & \multicolumn{2}{|c|}{ this study } & \multicolumn{2}{|c|}{ waste incineration } & \multicolumn{2}{|c|}{ e-waste facility } \\
\hline & soild samples & stack gas & fly $\operatorname{ash}^{a}$ & stack gas $^{b}$ & e-waste ${ }^{c}$ & dust $^{c}$ \\
\hline 6-ClBaP/1-ClPyr & $0.04-0.59$ & $0.09-0.77$ & 2.45 & 0.39 & 0.91 & 2.61 \\
\hline 3-ClFlu/1-ClPyr & $0.74-10.2$ & $0.22-17.6$ & 0.65 & 0.08 & 0.03 & 0.22 \\
\hline 7-ClBaA/1-ClPyr & $0.18-0.77$ & $0.06-0.84$ & 0.63 & 0.05 & 0.71 & 1.35 \\
\hline 6-ClBaP/3-ClFlu & $0.007-0.66$ & $0.02-0.68$ & 3.74 & 4.69 & 25.9 & 11.6 \\
\hline 1-ClPyr/3-ClFlu & $0.10-1.35$ & $0.06-4.50$ & 1.53 & 11.8 & 28.6 & 4.46 \\
\hline 7-ClBaA/3-ClFlu & $0.07-0.39$ & $0.03-0.52$ & 0.96 & 0.62 & 20.4 & 6.04 \\
\hline 7-BrBaA/1-BrPyr & $0.08-0.57$ & $0.06-0.68$ & 0.24 & & & \\
\hline 3-BrFlu/1-BrPyr & $0.58-4.01$ & $0.05-21.4$ & & & & \\
\hline 9-BrPhe/1-BrPyr & $0.41-3.93$ & $1.67-38.9$ & 2.22 & & & \\
\hline 7-BrBaA/3-BrFlu & $0.04-0.77$ & $0.01-1.79$ & & & & \\
\hline 1-BrPyr/3-BrFlu & $0.25-1.73$ & $0.05-18.6$ & & & & \\
\hline 9-BrPhe/3-BrFlu & $0.36-1.90$ & $0.78-31.2$ & & & & \\
\hline
\end{tabular}

${ }^{a}$ Data from Horri et $a ;^{2}{ }^{b}$ Data from Ohura et al; ${ }^{16}{ }^{c}$ Data from Ma et al; ${ }^{15}$ 

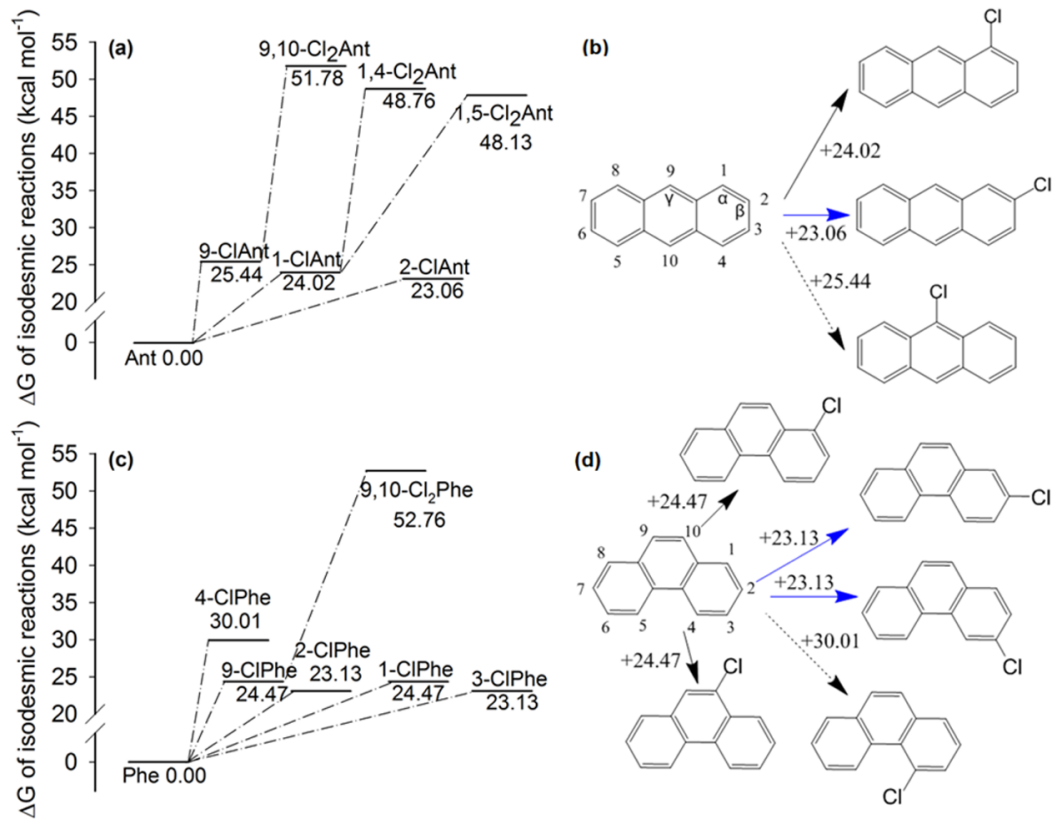

Figure 4. Relative Gibbs free energies of isodesmic reactions for successive chlorination of ClAnt and ClPhe congeners. (a): Relative Gibbs free energies of ClAnt formation; (b) Relative Gibbs free energies of ClAnt formation by chlorination at $\alpha, \beta, \gamma$ position of Ant; (c): Relative Gibbs free energies of ClPhe formation; (d): Relative Gibbs free energies of ClPhe formation by chlorination at 1, 2, 3, 4, 9 position of Phe. Blue arrows represent the easiest formation pathways; dotted arrows represent the most difficult formation pathways.

that the yield of Cl-PAHs from PAHs with $\mathrm{Cl}_{2}$ in the gas phase was much higher than that with $\mathrm{HCl}$ in the gas phase. ${ }^{51}$ A study on the formation of Cl-PAHs from PVC combustion also indicated that $\mathrm{HCl}$ produced from PVC combustion could be transformed into $\mathrm{Cl}_{2}$ and participate in the chlorination of PAHs. ${ }^{3}$ These two studies reported that the Cl-PAHs were formed by the chlorination of PAHs. In this study, PAHs from the secondary copper smelting processes were also quantified (SI Table S1 and Table S2). Deacon reactions with copper as the catalyst could possibly occur during this process, which would promote the transformation of $\mathrm{HCl}$ into $\mathrm{Cl}_{2}{ }^{26,52}$ Chlorination from PAHs during the secondary copper smelting process was expected. However, whether chlorination is the dominant formation pathway of $\mathrm{Cl}-\mathrm{PAHs}$ during secondary copper smelting is unknown.

Correlations between $\mathrm{Cl}-\mathrm{PAH}$ congeners and their parent $\mathrm{PAH}$ congeners were calculated to verify whether chlorination is the major formation pathway of Cl-PAHs during secondary copper smelting or not (SI Table S5). Only several congeners could correlate well with their parent $\mathrm{PAH}$ congeners. If chlorination of PAHs was the major formation pathway of $\mathrm{Cl}$ PAHs, we supposed that the correlation of Cl-PAH congeners with their corresponding parent $\mathrm{PAH}$ congeners were significant. However, the observed correlations were not significant, which indicated chlorination reactions of PAHs were not the dominant formation pathways of most Cl-PAH congeners during secondary copper smelting processes.

The relative Gibbs free energies of the formation of certain $\mathrm{Cl}-\mathrm{PAH}$ congeners from their parent $\mathrm{PAH}$ congeners were calculated based on isodesmic reactions. As more congeners of ClAnts and ClPhes were analyzed than other Cl-PAH homologues, formation of ClAnts and ClPhes from Ant and Phe, respectively, were used as examples (Figure 4). The formation of 9-chloroanthracene (9-ClAnt) from Ant would need more energy than the formation of 1-chloroanthracene (1ClAnt) and 2-chloroanthracene (2-ClAnt), which means the formation of 9-ClAnt would be more difficult. Similar with ClPhes, of which the formation of 2-ClPhe and 3chlorophenanthrene (3-ClPhe) would be easier than that of other monochlorinated congeners from Phe. Therefore, if chlorination was the major formation pathway of Cl-PAHs, then the concentration of 2-ClAnt should be higher than that of 9-ClAnt. Additionally, concentrations of 2-ClPhe and 3-ClPhe should be higher than 1-chlorophenanthrene (1-ClPhe) and 9ClPhe. Actually, as discussed above, the concentration of 9ClAnt was higher than that of 1-ClAnt and 2-ClAnt. Thus, direct chlorination of Ant may not be the major formation pathway of ClAnt during secondary copper smelting processes.

PAHs and Cl-PAHs tended to be formed in the cooling zone of industrial thermal processes. This was verified by PAH and $\mathrm{Cl}-\mathrm{PAH}$ concentrations being higher in fly ash collected at the end-of-pipe (after the cooling zone) than in slag collected at the bottom of the furnace. Previous studies suggested that high temperature favors the chlorination of PAHs, and thus promotes the formation of Cl-PAHs at higher temperatures through chlorination pathway. ${ }^{3,51}$ It is a cooling process for the stack gas when passed through the pipe. Thus, if chlorination of $\mathrm{PAHs}$ was the dominant formation pathway of Cl-PAH, the ratios of Cl-PAH versus $\mathrm{PAH}$ concentration in slag (a high temperature area) should be much higher than that in fly ash (a relative low temperature area). However, the ratios of $\mathrm{Cl}-\mathrm{PAH}$ versus $\mathrm{PAH}$ concentration in slag were about five times lower than that in fly ash, which indicated large quantities of Cl-PAHs formed in the cooling zone. This observation also hinted that chlorination of PAHs may not be the dominant formation pathway of Cl-PAHs. It was speculated that de novo synthesis, like that of $\mathrm{PCDD} / \mathrm{Fs}$ during industrial thermal processes, could also be a possible $\mathrm{Cl} / \mathrm{Br}-\mathrm{PAH}$ formation pathway. Further study regarding the formation mechanism of $\mathrm{Cl} / \mathrm{Br}$ PAHs is still needed.

The formation of brominated POPs seem to go through similar pathways as their chlorinated analogs. ${ }^{40}$ Correlations 

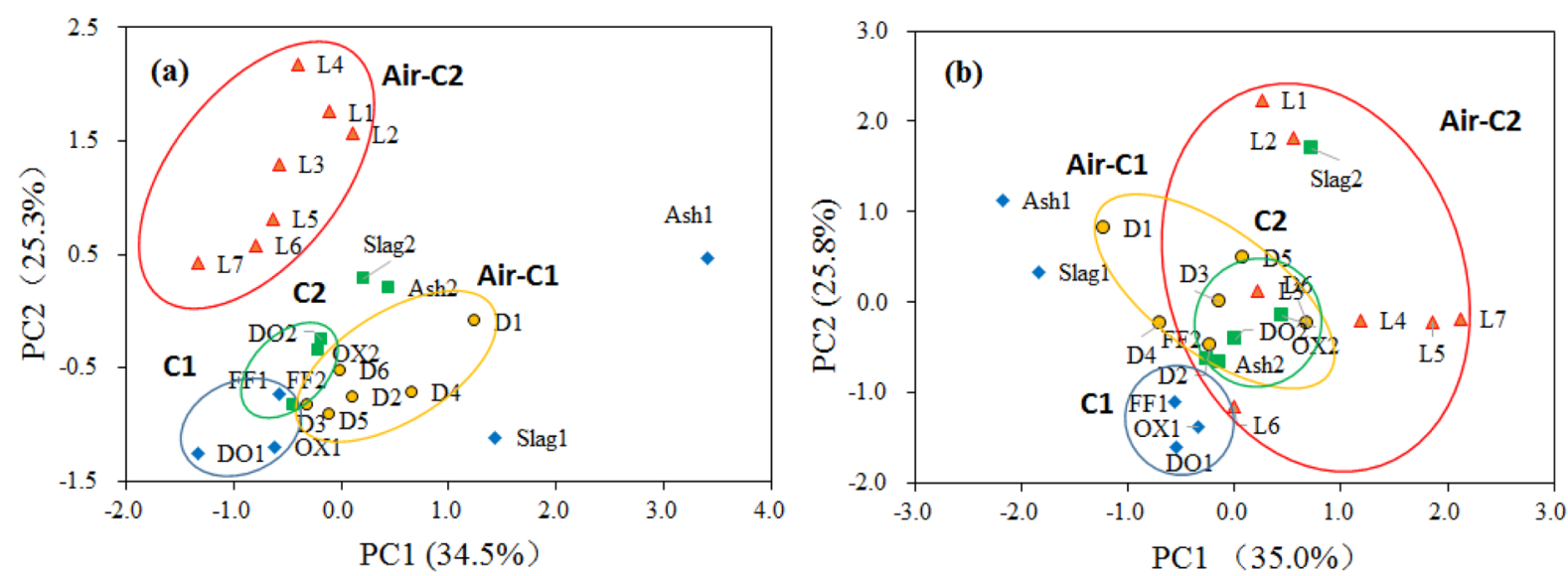

Figure 5. Principal component analysis of Cl-PAHs and Br-PAHs in stack gas, fly ash, slag, and air samples. (a) Cl-PAHs; (b) Br-PAHs. D1-6: air samples from plant C1; FF1, OX1, DO1: stack gas samples from plant C1; Ash1 and Slag1: solid samples from plant C1; L1-7: air samples from plant C2; FF2, OX2, DO2: stack gas samples from plant C2; Ash2 and Slag2: solid samples from plant C2.

between Br-PAH congeners and their parent PAH congeners were calculated, and significant correlations between most $\mathrm{Br}$ $\mathrm{PAH}$ congeners and their parent $\mathrm{PAH}$ congeners were not found (SI Table S5). The relative Gibbs free energies of formation for BrAnt and BrPhe congeners from their parent $\mathrm{PAH}$ congeners were also calculated based on isodesmic reactions (SI Table S6). For Ant derivatives, substituting the $\beta$ position was easier than $\alpha$ position. For Phe derivatives, the 2 and 3 positions were easier to be substituted than other positions. Therefore, similar to Cl-PAHs, concentrations of 2bromoanthracene (2-BrAnt) and 1-bromoanthracene (1BrAnt) should have been higher than 9-bromoanthracene (9BrAnt), and concentrations of 2-bromophenanthrene (2BrPhe) and 3-bromophenanthrene (3-BrPhe) should have been higher than 9-BrPhe if bromination of PAHs was the major formation pathway for Br-PAHs. This was different from the actual experimental congener distributions. Therefore, we speculated that bromination of PAHs was not the major formation pathway of Br-PAHs during secondary copper smelting processes.

Concentrations and Exposures of $\mathrm{Cl}-\mathrm{PAHs}$ and $\mathrm{Br}$ PAHs in Ambient Air. Analyzing the concentrations and characteristics of pollutants in ambient air samples was important for evaluating environmental and health risks. Air samples collected in the workplaces and surroundings of the smelting plants were analyzed for Cl-PAHs and Br-PAHs. Concentrations of $\sum_{19} \mathrm{Cl}$-PAHs and $\sum_{19} \mathrm{Br}$-PAHs were 29.0$604.7 \mathrm{pg} \mathrm{m}^{-3}$ and $2.2-34.7 \mathrm{pg} \mathrm{m}^{-3}$, respectively in the workplace air, and were $12.7-92.3 \mathrm{pg} \mathrm{m}^{-3}$ and $2.5-10.0 \mathrm{pg}$ $\mathrm{m}^{-3}$ in the surrounding air (SI Figure S2). Average concentrations of both Cl-PAHs and Br-PAHs in the workplace were obviously higher than those in the surroundings.

PCA analysis of the congener profiles of Cl-PAHs and $\mathrm{Br}$ PAHs in stack gas, solid residue, and ambient air samples was conducted to trace the sources of Cl-PAHs and Br-PAHs in ambient air. As shown in Figure 5, the influence of Cl-PAHs and Br-PAHs released by stack gas seemed to be much more obvious than that of solid residues. This was verified by fractions of gas-phase $\mathrm{Cl}-\mathrm{PAH}$ and $\mathrm{Br}-\mathrm{PAH}$ seing higher than that of the particulate phase. Therefore, it is significant to reduce stack gas emissions of $\mathrm{Cl}-\mathrm{PAHs}$ and $\mathrm{Br}-\mathrm{PAHs}$ from smelters with the aim of decreasing human exposure to $\mathrm{Cl}$ PAHs and Br-PAHs by air inhalation. Particle concentrations in the air samples collected in the workplace $\left(103-1025 \mu \mathrm{g} \mathrm{m}^{-3}\right)$ were higher than in the surrounding areas $\left(60-348 \mu \mathrm{g} \mathrm{m}^{-3}\right)$, which suggested that fugitive particles from the smelters may elevate the air levels of Cl-PAHs and Br-PAHs in the workplace (SI Figure S3). Higher fractions of particle-associated Cl-PAHs (15.5-65.5\%) and Br-PAHs (18.0-81.2\%) in the air of the workplace compared with that of Cl-PAHs $(2.5-35.7 \%)$ and Br-PAHs (12.6-53.3\%) in the air of surrounding areas also favored this assumption (SI Figure S4).

The exposures to atmospheric Cl-PAHs and Br-PAHs in the workplace and plant surroundings by air inhalation were evaluated. TEQ concentrations of Cl-PAHs and Br-PAHs in the workplace were $40.5-1193 \mathrm{fg}_{\mathrm{TEQ}} \mathrm{m}^{-3}$ and $0.58-18.3 \mathrm{fg}$ TEQ $\mathrm{m}^{-3}$, respectively. The TEQ concentrations were $63.7-192.4 \mathrm{fg}$ TEQ $\mathrm{m}^{-3}$ and 1.8-3.1 $\mathrm{fg}^{\mathrm{TEQ}} \mathrm{m}^{-3}$ in the surroundings for $\mathrm{Cl}-$ $\mathrm{PAHs}$ and $\mathrm{Br}-\mathrm{PAHs}$, respectively. TEQ concentrations of $\mathrm{Cl}-$ $\mathrm{PAHs}$ in the workplace were lower than PCDD/Fs, but at similar levels with PCBs and PCNs. ${ }^{53}$ Exposures to Cl-PAHs and Br-PAHs were calculated based on their TEQ concentrations ( $\mathrm{SI}$ eq S1). Inhalations of the Cl-PAHs and Br-PAHs were $0.76-22 \mathrm{fg}$ TEQ $\mathrm{kg}^{-1} \mathrm{~h}^{-1}$ and $0.01-0.34 \mathrm{fg}^{\mathrm{T}} \mathrm{TEQ} \mathrm{kg}^{-1}$ $\mathrm{h}^{-1}$, respectively, for the workers during working time. In regard to the residents around the smelting plants, the inhalations were $1.0-5.8 \mathrm{fg}$ TEQ $\mathrm{kg}^{-1} \mathrm{~h}^{-1}$ and $0.03-0.05 \mathrm{fg}$ TEQ $\mathrm{kg}^{-1} \mathrm{~h}^{-1}$ for Cl-PAHs and Br-PAHs, respectively. Estimation of the daily intake was based on $8 \mathrm{~h}$ of moderate working and $16 \mathrm{~h}$ of light activities/normal living around the plants. Average daily intake of Cl-PAHs and Br-PAHs were 121 fg TEQ $\mathrm{kg}^{-1} \mathrm{~d}^{-1}$ and $1.7 \mathrm{fg}$ TEQ $\mathrm{kg}^{-1} \mathrm{~d}^{-1}$, respectively, for workers, and $81 \mathrm{fg}$ TEQ $\mathrm{kg}^{-1} \mathrm{~d}^{-1}$ and $0.87 \mathrm{fg}$ TEQ $\mathrm{kg}^{-1} \mathrm{~d}^{-1}$, respectively, for residents. The daily intake of $\mathrm{Cl}-\mathrm{PAHs}$ and $\mathrm{Br}$ PAHs were much lower than the tolerable daily intake recommended by the WHO (1-4 pg TEQ $\mathrm{kg}^{-1} \mathrm{~d}^{-1}$ ) for dioxin. $^{54}$

\section{ASSOCIATED CONTENT}

\section{Supporting Information}

The Supporting Information is available free of charge on the ACS Publications website at DOI: 10.1021/acs.est.7b02031.

Equation S1, Table S1-S6, Figure S1-S4 (PDF) 


\section{AUTHOR INFORMATION}

\section{Corresponding Authors}

*(G.L.) Phone: 8610 62849356; fax: 8610 62849355; e-mail: grliu@rcees.ac.cn.

*(M.Z.) Phone: 8610 62849172; e-mail: zhengmh@rcees.ac. $\mathrm{cn}$.

\section{ORCID $\odot$}

Rong Jin: 0000-0001-9677-6177

Guorui Liu: 0000-0002-8462-6734

Minghui Zheng: 0000-0001-5270-6759

Notes

The authors declare no competing financial interest.

\section{ACKNOWLEDGMENTS}

This work was supported by the Chinese National 973 Program (2015CB453100), the National Natural Science Foundation of China (21477147, 91543108), the Strategic Priority Research Program of the Chinese Academy of Sciences (XDB14020102), and the Youth Innovation Promotion Association of the Chinese Academy of Sciences (2016038).

\section{REFERENCES}

(1) Falandysz, J.; Strandberg, B.; Strandberg, L.; Bergqvist, P. A.; Rappe, C. Concentrations and biomagnification of polychlorinated naphthalenes in black cormorants Phalacrocorax carbo sinensis from the Gulf of Gdansk, Baltic Sea. Sci. Total Environ. 1997, 204 (1), 97106.

(2) Horii, Y.; Ok, G.; Ohura, T.; Kannan, K. Occurrence and profiles of chlorinated and brominated polycyclic aromatic hydrocarbons in waste incinerators. Environ. Sci. Technol. 2008, 42 (6), 1904-1909.

(3) Wang, D. L.; Xu, X. B.; Chu, S. G.; Zhang, D. Analysis and structure prediction of chlorinated polycyclic aromatic hydrocarbons released from combustion of polyvinylchloride. Chemosphere 2003, 53 (5), 495-503.

(4) Fujima, S.; Ohura, T.; Amagai, T. Simultaneous determination of gaseous and particulate chlorinated polycyclic aromatic hydrocarbons in emissions from the scorching of polyvinylidene chloride film. Chemosphere 2006, 65 (11), 1983-1989.

(5) Niu, J. F.; Wang, L. L.; Yang, Z. F. QSPRs on photodegradation half-lives of atmospheric chlorinated polycyclic aromatic hydrocarbons associated with particulates. Ecotoxicol. Environ. Saf. 2007, 66 (2), 272-277.

(6) Ohura, T.; Morita, M.; Makino, M.; Amagai, T.; Shimoi, K. Aryl hydrocarbon receptor-mediated effects of chlorinated polycyclic aromatic hydrocarbons. Chem. Res. Toxicol. 2007, 20 (9), 1237-1241.

(7) Horii, Y.; Khim, J. S.; Higley, E. B.; Giesy, J. P.; Ohura, T.; Kannan, K. Relative Potencies of Individual Chlorinated and Brominated Polycyclic Aromatic Hydrocarbons for Induction of Aryl Hydrocarbon Receptor-Mediated Responses. Environ. Sci. Technol. 2009, 43 (6), 2159-2165.

(8) Ohura, T.; Sawada, K. I.; Amagai, T.; Shinomiya, M. Discovery of Novel Halogenated Polycyclic Aromatic Hydrocarbons in Urban Particulate Matters: Occurrence, Photostability, and AhR Activity. Environ. Sci. Technol. 2009, 43 (7), 2269-2275.

(9) Sun, J. L.; Ni, H. G.; Zeng, H. Occurrence of chlorinated and brominated polycyclic aromatic hydrocarbons in surface sediments in Shenzhen, South China and its relationship to urbanization. J. Environ. Monit. 2011, 13 (10), 2775-2781.

(10) Ohura, T.; Fujima, S.; Amagai, T.; Shinomiya, M. Chlorinated polycyclic aromatic hydrocarbons in the atmosphere: seasonal levels, gas-particle partitioning, and origin. Environ. Sci. Technol. 2008, 42 (9), 3296-3302.

(11) Koistinen, J.; Paasivirta, J.; Nevalainen, T.; Lahtipera, M. Chlorinated fluorenes and alkylflurenes in bleached kraft pulp and pulp-mill discharges. Chemosphere 1994, 28 (12), 2139-2150.
(12) Haglund, P.; Alsberg, T.; Bergman, A.; Jansson, B. Analysis of halogenated polyclic aromatic-hydrocarbons in urban air, snow and automobile exhaust. Chemosphere 1987, 16 (10-12), 2441-2450.

(13) Ieda, T.; Ochiai, N.; Miyawaki, T.; Ohura, T.; Horii, Y. Environmental analysis of chlorinated and brominated polycyclic aromatic hydrocarbons by comprehensive two-dimensional gas chromatography coupled to high-resolution time-of-flight mass spectrometry. J. Chromatogr. A 2011, 1218 (21), 3224-3232.

(14) Sun, J. L.; Zeng, H.; Ni, H. G. Halogenated polycyclic aromatic hydrocarbons in the environment. Chemosphere 2013, 90 (6), 17511759.

(15) Ma, J.; Horii, Y.; Cheng, J.; Wang, W.; Wu, Q.; Ohura, T.; Kannan, K. Chlorinated and parent polycyclic aromatic hydrocarbons in environmental samples from an electronic waste recycling facility and a chemical industrial complex in China. Environ. Sci. Technol. 2009, 43 (3), 643-649.

(16) Ohura, T.; K, A.; Amagai, T.; Shinomiya, M. Relationships between chlorinated polycyclic aromatic hydrocarbons and dioxins in urban air and incinerators. Organohalogen Compd. 2007, 69, 29022905.

(17) Weber, R.; Iino, F.; Imagawa, T.; Takeuchi, M.; Sakurai, T.; Sadakata, M. Formation of PCDF, PCDD, PCB, and PCN in de novo synthesis from $\mathrm{PAH}$ : Mechanistic aspects and correlation to fluidized bed incinerators. Chemosphere 2001, 44 (6), 1429-1438.

(18) Iino, F.; Imagawa, T.; Takeuchi, M.; Sadakata, M.; Weber, R. Formation rates of polychlorinated dibenzofurans and dibenzo-pdioxins from polycyclic aromatic hydrocarbons, activated carbon and phenol. Chemosphere 1999, 39 (15), 2749-2756.

(19) Wang, J.; Chen, S.; Tian, M.; Zheng, X.; Gonzales, L.; Ohura, T.; Mai, B.; Simonich, S. L. Inhalation cancer risk associated with exposure to complex polycyclic aromatic hydrocarbon mixtures in an electronic waste and urban area in South China. Environ. Sci. Technol. 2012, 46 (17), 9745-9752.

(20) Hu, J. C.; Zheng, M. H.; Nie, Z. Q.; Liu, W. B.; Liu, G. R.; Zhang, B.; Xiao, K. Polychlorinated dibenzo-p-dioxin and dibenzofuran and polychlorinated biphenyl emissions from different smelting stages in secondary copper metallurgy. Chemosphere 2013, 90 (1), 8994.

(21) Ba, T.; Zheng, M.; Zhang, B.; Liu, W.; Xiao, K.; Zhang, L. Estimation and characterization of $\mathrm{PCDD} / \mathrm{Fs}$ and dioxin-like PCBs from secondary copper and aluminum metallurgies in China. Chemosphere 2009, 75 (9), 1173-8.

(22) Guidance on best available techniques and best environmental practices for the recycling and waste disposal of articles containing polybrominated diphenyl ethers (PBDEs) listed under the Stockholm Convention; http://chm.pops.int/Implementation/NIPs/Guidance/ GuidanceonBATBEPfortherecyclingofPBDEs/tabid/3172/Default. aspx.

(23) Nganai, S.; Lomnicki, S. M.; Dellinger, B. Formation of PCDD/ Fs from the Copper Oxide-Mediated Pyrolysis and Oxidation of 1,2Dichlorobenzene. Environ. Sci. Technol. 2011, 45 (3), 1034-1040.

(24) Ryu, J. Y.; Mulholland, J. A.; Chu, B. Chlorination of dibenzofuran and dibenzo-p-dioxin vapor by copper (II) chloride. Chemosphere 2003, 51 (10), 1031-1039.

(25) Ryu, J. Y.; Choi, K. C.; Mulholland, J. A. Polychlorinated dibenzo-p-dioxin (PCDD) and dibenzofuran (PCDF) isomer patterns from municipal waste combustion: formation mechanism fingerprints. Chemosphere 2006, 65 (9), 1526-36.

(26) Jiang, X. X.; Liu, G. R; Wang, M.; Zheng, M. H. Fly ashmediated formation of polychlorinated naphthalenes during secondary copper smelting and mechanistic aspects. Chemosphere 2015, 119, 1091-8.

(27) Mei, W.; Guorui, L.; Xiaoxu, J.; Wenbin, L.; Li, L.; Sumei, L.; Minghui, Z.; Jiayu, Z. Brominated dioxin and furan stack gas emissions during different stages of the secondary copper smelting process. Atmos. Pollut. Res. 2015, 6 (3), 464-468.

(28) Ba, T.; Zheng, M. H.; Zhang, B.; Liu, W. B.; Su, G. J.; Liu, G. R.; Xiao, K. Estimation and congener-specific characterization of polychlorinated naphthalene emissions from secondary nonferrous 
metallurgical facilities in china. Environ. Sci. Technol. 2010, 44 (7), 2441-2446.

(29) Report on the Development of China's Recycling Nonferrous Metals Industry in 2015; China Nonferrous Metals Industry Association: Beijing, 2016.

(30) Liu, G.; Jiang, X.; Wang, M.; Dong, S.; Zheng, M. Comparison of $\mathrm{PCDD} / \mathrm{F}$ levels and profiles in fly ash samples from multiple industrial thermal sources. Chemosphere 2015, 133, 68-74.

(31) Liu, G. R.; Cai, Z. W.; Zheng, M. H. Sources of unintentionally produced polychlorinated naphthalenes. Chemosphere 2014, 94, 1-12.

(32) Jiang, X. X.; Liu, G. R.; Wang, M.; Liu, W. B.; Tang, C.; Li, L.; Zheng, M. H. Case study of polychlorinated naphthalene emissions and factors influencing emission variations in secondary aluminum production. J. Hazard. Mater. 2015, 286, 545-52.

(33) Hu, J.; Zheng, M.; Liu, W.; Li, C.; Nie, Z.; Liu, G.; Xiao, K.; Dong, S. Occupational Exposure to Polychlorinated Dibenzo-p-dioxins and Dibenzofurans, Dioxin-like Polychlorinated Biphenyls, and Polychlorinated Naphthalenes in Workplaces of Secondary Nonferrous Metallurgical Facilities in China. Environ. Sci. Technol. 2013, 47 (14), 7773-7779.

(34) Jin, R.; Liu, G.; Jiang, X.; Liang, Y.; Fiedler, H.; Yang, L.; Zhu, Q.; Xu, Y.; Gao, L.; Su, G.; Xiao, K.; Zheng, M. Profiles, sources and potential exposures of parent, chlorinated and brominated polycyclic aromatic hydrocarbons in haze associated atmosphere. Sci. Total Environ. 2017, 593-594, 390-398.

(35) Zhao, Y.; Zhan, J.; Liu, G.; Ren, Z.; Zheng, M.; Jin, R.; Yang, L.; Wang, M.; Jiang, X.; Zhang, X. Field study and theoretical evidence for the profiles and underlying mechanisms of $\mathrm{PCDD} / \mathrm{F}$ formation in cement kilns co-incinerating municipal solid waste and sewage sludge. Waste Manage. 2016, 61, 337-344.

(36) Zeng, X. L.; Wang, Y.; Zhang, X. L.; Yu, Y. S. Density functional theory studies on the molecular structures and thermodynamic properties of polychlorinated anthracenes. J. Mol. Struct.: THEOCHEM 2009, 906 (1-3), 83-86.

(37) Sharma, A.; Pushpa, K. K.; Dhanya, S.; Naik, P. D.; Bajaj, P. N. Rate coefficients and products for gas-phase reactions of chlorine atoms with cyclic unsaturated hydrocarbons at $298 \mathrm{~K}$. Int. J. Chem. Kinet. 2010, 42 (2), 98-105.

(38) Spicer, C. W.; Chapman, E. G.; Finlayson-Pitts, B. J.; Plastridge, R. A.; Hubbe, J. M.; Fast, J. D.; Berkowitz, C. M. Unexpectedly high concentrations of molecular chlorine in coastal air. Nature 1998, 394 (6691), 353-356.

(39) Wang, M.; Liu, G.; Jiang, X.; Xiao, K.; Zheng, M. Formation and potential mechanisms of polychlorinated dibenzo-p-dioxins and dibenzofurans on fly ash from a secondary copper smelting process. Environ. Sci. Pollut. Res. 2015, 22 (11), 8747-55.

(40) Wang, M.; Liu, G.; Jiang, X.; Zheng, M.; Yang, L.; Zhao, Y.; Jin, R. Thermochemical Formation of Polybrominated Dibenzo-p-Dioxins and Dibenzofurans Mediated by Secondary Copper Smelter Fly Ash, and Implications for Emission Reduction. Environ. Sci. Technol. 2016, 50 (14), 7470-7479.

(41) Jiang, X.; Liu, G.; Wang, M.; Zheng, M. Formation of Polychlorinated Biphenyls on Secondary Copper Production Fly Ash: Mechanistic Aspects and Correlation to Other Persistent Organic Pollutants. Sci. Rep. 2015, 5, 13903.

(42) Jin, R.; Zhan, J. Y.; Liu, G. R.; Zhao, Y. Y.; Zheng, M. H. Variations and factors that influence the formation of polychlorinated naphthalenes in cement kilns co-processing solid waste. J. Hazard. Mater. 2016, 315, 117-125.

(43) Wyrzykowska-Ceradini, B.; Gullett, B. K.; Tabor, D.; Touati, A. PBDDs/Fs and PCDDs/Fs in the Raw and Clean Flue Gas during Steady State and Transient Operation of a Municipal Waste Combustor. Environ. Sci. Technol. 2011, 45 (13), 5853-5860.

(44) Chen, Y.; Bi, X.; Mai, B.; Sheng, G.; Fu, J. Emission characterization of particulate/gaseous phases and size association for polycyclic aromatic hydrocarbons from residential coal combustion. Fuel 2004, 83 (7-8), 781-790.

(45) Laumann, S.; Micić, V.; Kruge, M. A.; Achten, C.; Sachsenhofer, R. F.; Schwarzbauer, J.; Hofmann, T. Variations in concentrations and compositions of polycyclic aromatic hydrocarbons (PAHs) in coals related to the coal rank and origin. Environ. Pollut. 2011, 159 (10), 2690-2697.

(46) Zhou, H. C.; Jin, B. S.; Zhong, Z. P.; Huang, Y. J.; Xiao, R.; Li, D. J. Investigation of polycyclic aromatic hydrocarbons from coal gasification. J. Environ. Sci. 2005, 17 (1), 141-145.

(47) Luna, F. M. T.; Pontes Filho, A. A.; Trindade, E. D.; Cavalcante, C. L., Jr., Rapid assessment of total and polycyclic aromatic contents in heavy oils. Environ. Monit. Assess. 2016, 188, (4).10.1007/s10661-0165213-7

(48) Adams, J.; Bornstein, J. M.; Munno, K.; Hollebone, B.; King, T.; Brown, R. S.; Hodson, P. V. Identification of compounds in heavy fuel oil that are chronically toxic to rainbow trout embryos by effectsdriven chemical fractionation. Environ. Toxicol. Chem. 2014, 33 (4), 825-835.

(49) Ma, J.; Chen, Z. Y.; Wu, M. H.; Feng, J. L.; Horii, Y.; Ohura, T.; Kannan, K. Airborne PM2.5/PM10-Associated Chlorinated Polycyclic Aromatic Hydrocarbons and their Parent Compounds in a Suburban Area in Shanghai, China. Environ. Sci. Technol. 2013, 47 (14), 76157623.

(50) Ohura, T.; Horii, Y.; Kojima, M.; Kamiya, Y. Diurnal variability of chlorinated polycyclic aromatic hydrocarbons in urban air, Japan. Atmos. Environ. 2013, 81, 84-91.

(51) Yoshino, H.; Urano, K. Formation of chlorinated PAHs in exhaust gas from municipal waste incinerators, and their mutagenic activities. Toxicol. Environ. Chem. 1997, 63 (1-4), 233-246.

(52) Procaccini, C.; Bozzelli, J. W.; Longwell, J. P.; Smith, K. A.; Sarofim, A. F. Presence of chlorine radicals and formation of molecular chlorine in the post-flame region of chlorocarbon combustion. Environ. Sci. Technol. 2000, 34 (21), 4565-4570.

(53) Hu, J. C.; Zheng, M. H.; Liu, W. B.; Li, C. L.; Nie, Z. Q.; Liu, G. R; Xiao, K.; Dong, S. J. Occupational Exposure to Polychlorinated Dibenzo-p-dioxins and Dibenzofurans, Dioxin-like Polychlorinated Biphenyls, and Polychlorinated Naphthalenes in Workplaces of Secondary Nonferrous Metallurgical Facilities in China. Environ. Sci. Technol. 2013, 47 (14), 7773-7779.

(54) van Leeuwen, F. X. R.; Feeley, M.; Schrenk, D.; Larsen, J. C.; Farland, W.; Younes, M. Dioxins: WHO's tolerable daily intake (TDI) revisited. Chemosphere 2000, 40 (9-11), 1095-1101. 